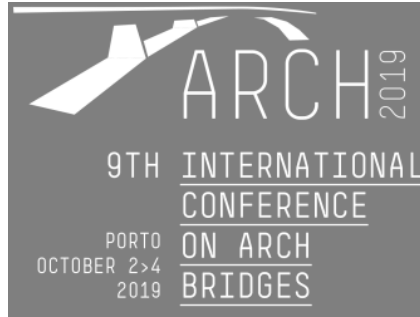

\title{
Modeling the Behavior of Radially Pinned Brick Triplets
}

\author{
Jonathan Haynes ${ }^{10000-0002-7364-9447]}$, Ahmed Naggasa ${ }^{1}$, Levingshan Augusthus- \\ Nelson ${ }^{1[0000-0003-3092-7635]}$, Feras El-Basir ${ }^{1}$ and Abdulaziz Alsaleh ${ }^{1}$ \\ ${ }^{1}$ Directorate of Civil Engineering, University of Salford, Salford, United Kingdom \\ b.j.haynesesalford.ac.uk
}

\begin{abstract}
The continued use of many UK highway and railway masonry arch bridges is dependent upon maintaining robustness as the materials deteriorate over time. A common failure in multi-ring brickwork arches subject to fatigue, is ring separation.

This paper offers some early results from an investigation of a ring separation repair technique involving radial pinning. Triplet testing is used to establish and compare the structural behavior of two types of shear reinforcement, which are validated by finite element modelling. Conclusions are drawn which are potentially of significant practical interest to masonry arch bridge owners and assessors.
\end{abstract}

Keywords: Masonry, ring separation, shear reinforcement.

\section{Introduction}

\subsection{Background and History}

There are approximately 40,000 masonry arch bridges currently in service in the UK. Around $60 \%$ of these bridges are over 100 years old [1] which demonstrates the durability of masonry as a construction material. The majority of UK masonry arch bridges are owned by navigable waterway, highway and railway authorities [2]. However, because of loading increases and inevitable material degradation, these bridges require assessment and possibly repair.

When arches are strained, axial stresses are induced in the brickwork [3]. In multiring arches, the rings are of different lengths and the axial shortening will vary between the rings; this induces longitudinal shear stresses between the rings, so that composite action must develop. Multi-ring arches without headers must transfer longitudinal shear for composite action through the mortar bed only, so there is greater propensity to ring separation or de-lamination occurring. Since shear is a shape distortional stress, greatest shear stresses accompany the greatest displacements of the arch barrel. Logically, as permissible axle loads increase, so too will displacements and shear stresses.

Under cyclic loading there is an endurance limit associated with each load level [4]. Endurance drops exponentially as the applied load approaches the arch capacity. 


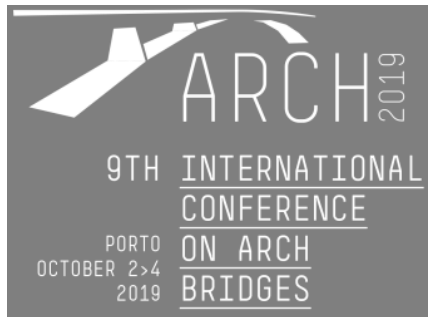

Once ring separation occurs, the arch barrel must resist loading as separate rings, which will experience reduced direct and longitudinal shear capacity. This gives way to the observation that high-stress low-cycle loading is likely to generate a hinged collapse mechanism failure but low-stress high-cycle loading is likely to generate a ring separation failure in multi-ring masonry arches. Full scale tests [5] show that ring separation of a whole ring can lead to a capacity reduction in excess of $50 \%$.

Investigations of arch capacity change due to ring separation in cyclically loaded multi-ring masonry arches [4] show that cyclic loading below 50\% first crack load produced no deleterious effects; increasing the load above the first crack load induced ring separation. Arches which had ring separated, suffered further propagation even when the load was below first hinge load. This suggests that any multi-ring brickwork masonry arch which does not contain headers and has developed at least one hinge in its life will fail prematurely by ring separation, rather than a classical four hinge collapse mechanism.

This paper addresses a possible remedial solution to this problem using radial pinning, which is intended to mechanically resist slip between arch rings. Figure 1 depicts ring separation and the proposed repair. Radial pinning is considered to be an advantageous remedial repair because it requires access to the arch intrados only.
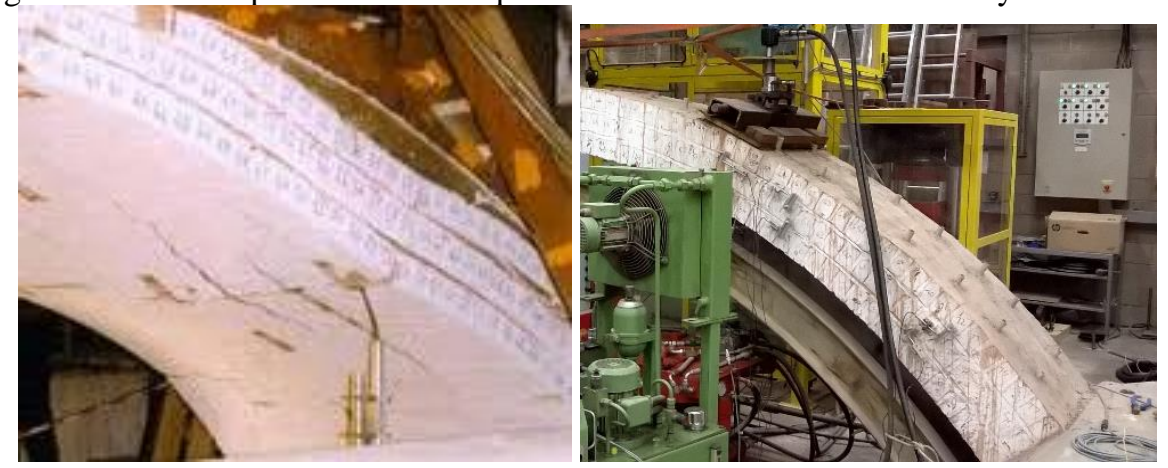

Fig. 1. Ring separation and radial pinning.

\section{Test Methodology}

In order to compare the efficiency of various radial pinning systems, unreinforced and reinforced brick triplets were tested in shear. Though cyclic loading is known to be affected by pre-compression [9], only the unreinforced triplets were tested with precompression.

Full scale testing of brick triplets was undertaken to compare the performance of a solid $10 \mathrm{~mm}$ diameter threaded mild steel bar and hollow $25 \mathrm{~mm}$ diameter plain aluminum tube, as radial pinning.

\subsection{Constituent Material Testing}

Initial testing of the bricks and mortar for compressive strength resulted in the data shown in Table 1. The mortar mix was 1:2:9 (OPC: lime: sand), the sand was oven 
dried. The bricks used were Class A, Staffordshire Red, manufactured by the Ketley Brick Company. This combination of strong brick and sand rich (weak) mortar was chosen to establish a pessimistic shear strength [6, $7 \& 8$ ] and ensure a mortar or mortar-brick failure.

Table 1. Material test data.

\begin{tabular}{lccc}
\hline Heading level & $\begin{array}{c}\text { Average compressive } \\
\text { strength }\left(\mathrm{N} / \mathrm{mm}^{2}\right)\end{array}$ & $\begin{array}{c}\text { Average tensile } \\
\text { strength }\left(\mathrm{N} / \mathrm{mm}^{2}\right)\end{array}$ & Sample size \\
\hline Brick & 154 & & 3 \\
Mortar & 1.08 & & 6 \\
Mild steel bar & & 517 & 3 \\
Aluminum tube & & 225 & 3 \\
\hline
\end{tabular}

\subsection{Triplet manufacture}

The triplets were manufactured by students using standardized equipment, designed to reduce variation in materials and workmanship. Initial testing identified a mortar mix which had good workability, and precise water content. The triplets were air cured for 14 days before testing.

Holes for radial pins were predrilled in the bricks and blocked out with a flexible pack during triplet manufacture. The holes in reinforced triplets were then cleaned and filled with EasyFix Polyester Resin masonry adhesive and a reinforcing bar. The holes were overfilled with adhesive to ensure a full bonding surface. Adhesive was allowed to cure for 24 hours before testing.

\subsection{Triplet Tests}

All samples were tested to ultimate failure using a $250 \mathrm{kN}$ ZwickRoel universal compression test machine, which automatically logged force and displacement data, as depicted in Figure 2. Displacement across individual joints was logged using LVDT's.

Unreinforced triplets were tested in direct shear; ten with, and ten without a lateral pre-compression of $2.0 \mathrm{kN}$.

Reinforced triplets were all tested without pre-compression. Five samples were reinforced with threaded $10 \mathrm{~mm}$ diameter steel bar, ten were reinforced with $25 \mathrm{~mm}$ diameter aluminum tube. 


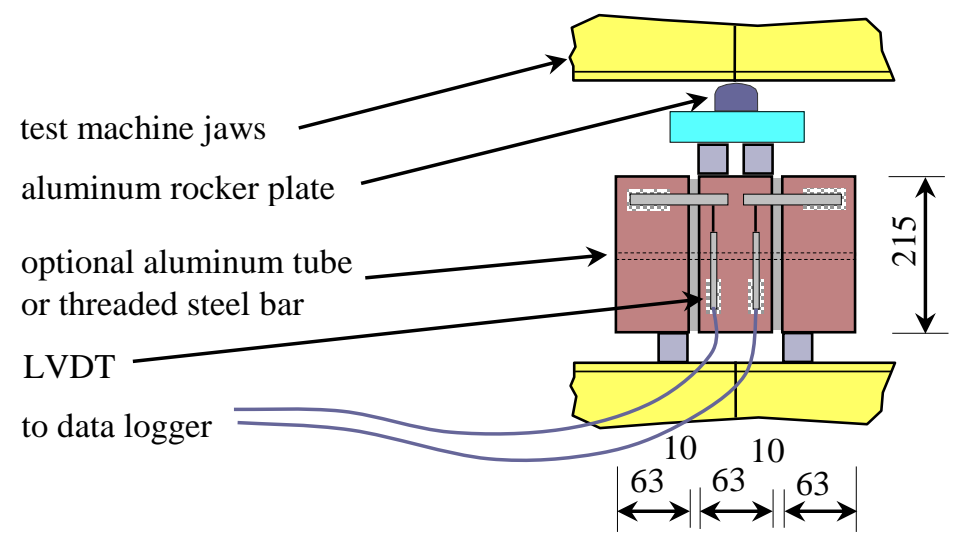

Fig. 2. Triplet test arrangement.

\section{$3 \quad$ Numerical Modelling}

Finite element models were created using ABAQUS 6.13 software. This was developed to represent the shear interaction of a triplet and investigate the effect of composite action from the reinforcing bars. Static analysis was used.

\subsection{Geometry}

The brick dimensions were taken from averaged measurements of a batch of bricks. The mortar thickness was nominally set at $10 \mathrm{~mm}$ by the method of triplet manufacture. An unreinforced FEA model is shown in Figure 3.

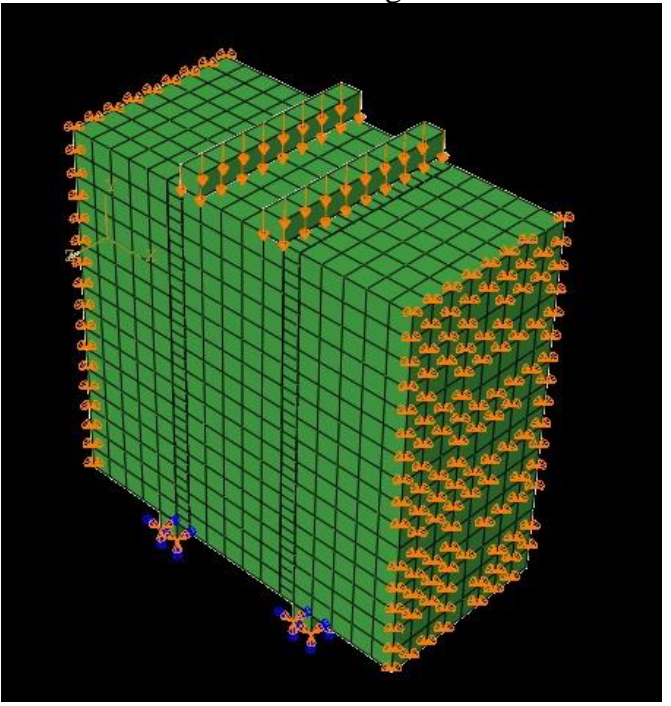

Fig. 3. Un-reinforced triplet finite element model. 


\subsection{Material Properties}

To represent the observed failure mechanism in the physical tests, the bricks were modelled as linear elastic brick elements, of Young's Modulus of Elasticity 7000 $\mathrm{N} / \mathrm{mm}^{2}$ and Poisson's ratio 0.2.

Mortar [10] was modelled as an elasto-plastic material using Mohr-Coulomb plasticity, $\phi=30.5^{\circ}$, dilation angle ranged between $2^{\circ}$ and $10^{\circ}$.

Steel and aluminum reinforcement were modelled as linear elastic materials, as were the steel support bars.

\subsection{Connectivity}

The bond between brick and mortar was modelled as a rough friction interaction interface, which infers an infinite coefficient of friction in the tangential stress direction. In the normal stress direction, the classical Lagrange multiplier method was applied to model hard contact. This means that displacements were limited to elastic slip only.

The interface between brick and reinforcement was modelled as a surface to surface tie constraint (there is no relative motion between the surfaces), where the brick was the master surface.

\subsection{Restraints and Loading}

The triplet model was supported on mild steel bar elements, which were rigidly fixed at the base. Similarly, loading was applied as forced displacement at mild steel bar elements at the top of the triplet model.

For models with pre-compression, one side of the triplet was constrained to move vertically only; the other side being loaded with a prescribe force of $2.0 \mathrm{kN}$.

\section{$4 \quad$ Results and Discussion}

Typical force and displacement data logged during testing is shown in Figure 4.

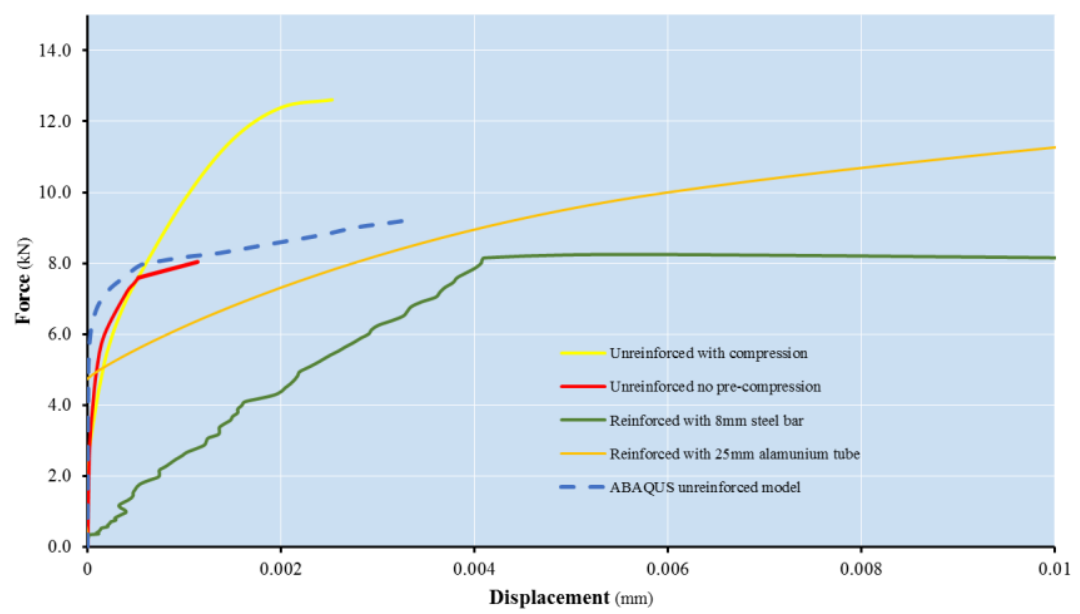

Fig. 4. Typical force $v$ displacement plot for four types of triplets and an FEA model [11 \& 12]. 


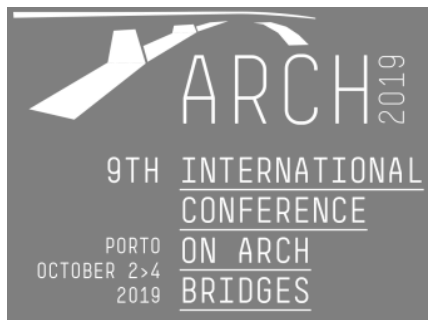

Figure 4 also includes the force-displacement characteristic predicted by the FEA model. The fundamentally different structural behavior of reinforced and unreinforced samples is indicated by the initial slope and peak values obtained.

During the test it was observed that distinctly different failure modes occurred in the steel bar and aluminum tube reinforced triplets. As can be seen in Figure 5, the bar reinforced triplets failed by shear of the $10 \mathrm{~mm}$ diameter steel bar, following cracking between the mortar and bricks. However, the tube reinforced triplets failed by splitting of the brick, following cracking between the mortar and bricks, with little permanent deformation of the $25 \mathrm{~mm}$ diameter tube.
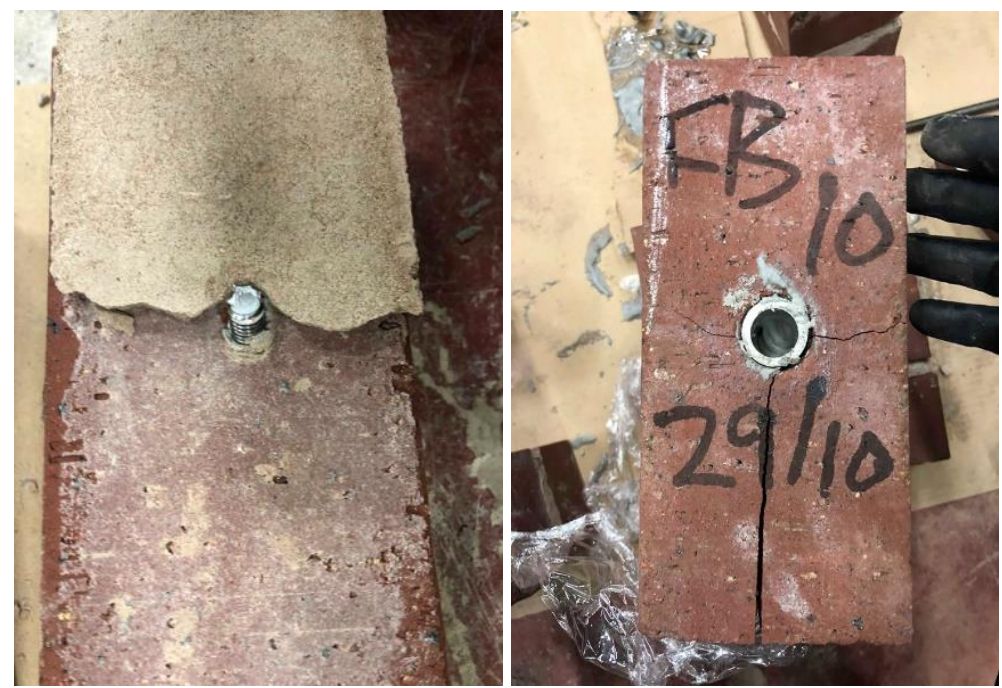

Fig. 5. Failure mechanisms identified in a) bar reinforced, and b) tube reinforced triplets [12].

The reinforced triplets also displayed significantly more ductility than the unreinforced triplets. The $10 \mathrm{~mm}$ diameter mild steel bar reinforced triplets exhibited a near perfect elasto-plastic characteristic, which suggests the shear failure of the mild steel bar dominates the behavior of the joint.

However, the $25 \mathrm{~mm}$ diameter aluminum tube reinforced triplets exhibited a forcedisplacement characteristic which was initially very similar to an un-reinforced sample but extended to achieve four times the failure capacity and over 100 times the failure strain. This suggests that initial response is governed by the mortar stiffness, and once this bond is broken the aluminum tube deforms until the shear stiffness of the brick is mobilized. 


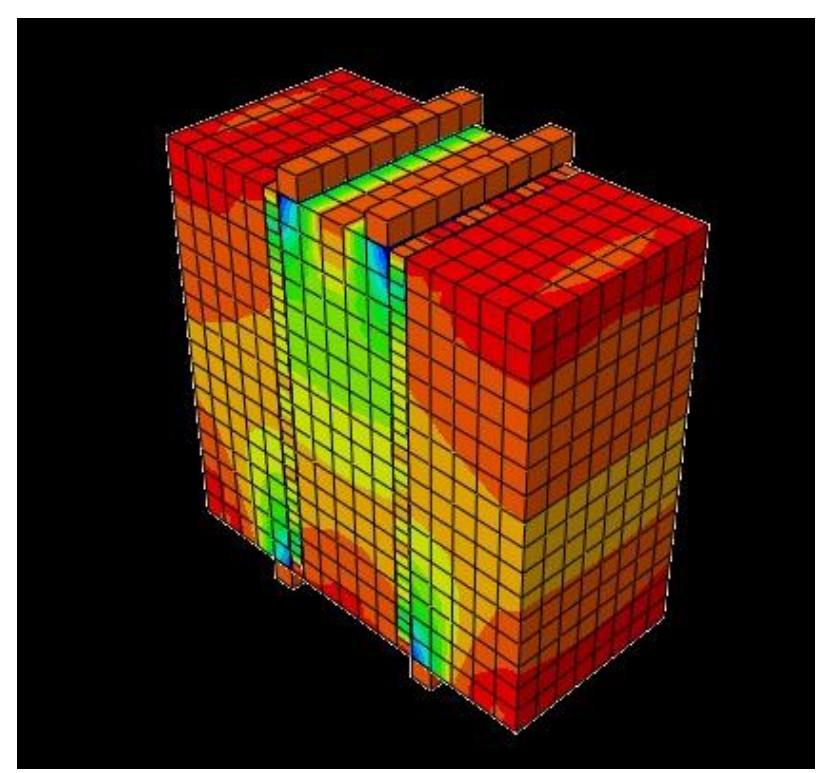

Fig. 6. Vertical strain field for a deformed unreinforced triplet.

The ABAQUS modelling of brick triplets produced a good representation of the force-displacement characteristic although the initial elastic response persisted for longer than observed in the tests. Similarly, the final plastic strain was twice that observed in the tests. Although this may appear to be a significant shortcoming, the relative size of the observed displacements at initial slip is very small (in the order of thousands of a millimeter).

The use of Mohr-Coulomb plasticity with a small dilation angle produces a model which requires a great deal of time to solve, particularly when high levels of precompression are applied. This is because the mortar must deform (crush) transversely before vertical slip can initiate.

\section{Conclusion}

There is clear evidence that grouted reinforcement can reinstate the longitudinal shear capacity of a multi-ring masonry arch which has suffered ring separation.

Testing results suggest that use of a small diameter mild steel bar will produce shear failure in the radial pin but use of a larger diameter radial pin will change the failure mechanism to splitting of the brick.

Although radial pinning is clearly a simple and efficient method of rehabilitation for ring separated arches, the choice of pin size and type must be made carefully in order to avoid a future failure which is unacceptable to the bridge owner.

The endurance capacity of reinforced triplets under cyclic loading must now be investigated and validated against full scale arch tests. 


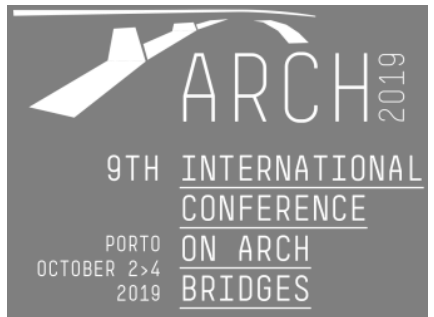

\section{References}

1. Melbourne, C., McKibbins, L.D., Sawar, N. \& Sicilia Gaillard, C.: Masonry arch bridges: condition appraisal and remedial treatment C656. CIRIA, London (2006).

2. Melbourne, C., Wang, J. \& Tomor, A.K.: A new masonry arch bridge assessment strategy (SMART). Proceedings of the ICE - Bridge Engineering, 160(2), 81-87 (2007).

3. Humphrey, D. G.: Assessment of radial tying as a technique to rehabilitate arch bridges exhibiting ring separation. M.Sc Dissertation, University of Salford, (2007).

4. Melbourne, C. \& Alnumaimi, M. M.: The behaviour of multi-ring brickwork arches subjected to cyclic loading. In: ARCH'01 - $3^{\text {rd }}$ International Conference on Arch Bridges, Paris, pp. 243-247 (2001).

5. Melbourne, C. \& Gilbert, M.: The behaviour of multi-ring brickwork arch bridges containing ring separation. British Masonry Society Proceedings (4), 218-222 (1994).

6. Shetty, N., Livitsanos, G., Aggelis, D., van Hemelrijck, D., Wevers, M., van Balen, K., \& Verstrynge, E.: Visualization of crack propogation in brick masonry couplets under compression. In: $10^{\text {th }}$ International Masonry Conference. Milan, Italy, pp. 1557-1566 (2018).

7. Begimgil, M.: Compressive stress-strain characteristics of model brick masonry prisms constructed with differenet types of mortar additives. In: $10^{\text {th }}$ International Masonry Conference. Milan, Italy, pp. 1396-1403 (2018).

8. Vermeltfoort, A.T.: Variation in shear properties of masonry. In: $8^{\text {th }}$ International Masonry Conference. Dresden, Germany, pp. 159-168 (2010).

9. Mojsilovic, N., Simundic, G. \& Page, A.: Load tests on masonry wallettes subjected to cyclic shear. In: $8^{\text {th }}$ International Masonry Conference. Dresden, Germany, pp. 487-496 (2010).

10. Naggasa, A., Augusthus-Nelson, L. \& Haynes, J.: Use of finite element analysis to investigate the structural behaviour of masonry arch bridges subject to foundation settlement. In: $10^{\text {th }}$ International Masonry Conference. Milan, Italy, pp. 518-526 (2018).

11. Alsaleh, A.: Behaviour of unreinforced brick triplets in shear. B.Eng Dissertation, University of Salford, (2019).

12. El-Basir, F.: Behaviour of reinforced brick triplets in shear. B.Eng Dissertation, University of Salford, (2019). 


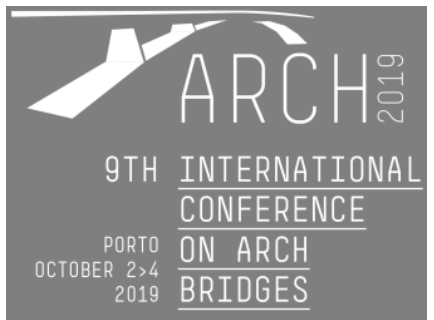

\title{
Modeling the Behavior of Radially Pinned Brick Triplets
}

\author{
Jonathan Haynes ${ }^{10000-0002-7364-9447]}$, Ahmed Naggasa ${ }^{1}$, Levingshan Augusthus- \\ Nelson ${ }^{1[0000-0003-3092-7635]}$, Feras El-Basir ${ }^{1}$ and Abdulaziz Alsaleh ${ }^{1}$ \\ ${ }^{1}$ Directorate of Civil Engineering, University of Salford, Salford, United Kingdom \\ b.j.haynesesalford.ac.uk
}

Keywords: Masonry, ring separation, shear reinforcement.

\section{Introduction}

There are approximately 40,000 masonry arch bridges in the UK transport networks, and their continued use depends upon adequate maintenance.

When arches are strained, axial stresses are induced in the brickwork. In multi-ring arches, the rings are of different lengths and the axial shortening will vary between the rings; this induces longitudinal shear stresses between the rings, so that composite action must develop. Multi-ring arches without headers must transfer longitudinal shear for composite action through the mortar bed only, so there is greater propensity to ring separation occurring [1]. Full scale tests [2] show that ring separation of a whole ring can lead to a capacity reduction in excess of 50\%. This paper addresses a possible remedial solution to this problem using radial pinning. Radial pinning is considered to be an advantageous remedial repair because it requires access to the arch intrados only.

\section{Methodology}

In order to compare the efficiency of solid $10 \mathrm{~mm}$ diameter threaded mild steel bar and hollow $25 \mathrm{~mm}$ diameter plain aluminum tube as radial pinning systems, unreinforced and reinforced brick triplets were tested in shear. Unreinforced triplets were also tested with pre-compression.

The mortar mix was 1:2:9 (OPC: lime: sand), using oven dried sand and a prescribed water content. The bricks used were Class A, Staffordshire Red. This combination of strong brick and sand rich (weak) mortar was chosen to establish a pessimistic shear strength and ensure a mortar or mortar-brick failure mechanism. Holes for radial pins were predrilled in the bricks.

Finite element models were created using ABAQUS to represent the shear interaction of a triplet and investigate the effect of composite action from the reinforcing bars. Static analysis was used. The mortar [3] was modelled as an elasto-plastic material using Mohr-Coulomb plasticity. The bond between 


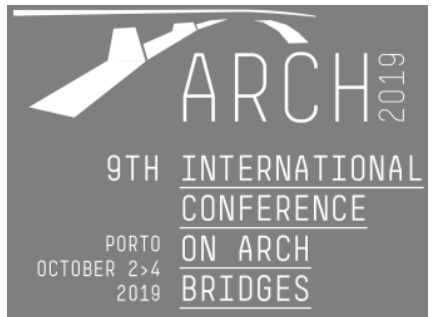

brick and mortar was modelled as a rough friction interaction interface. The interface between brick and reinforcement was modelled as a surface to surface tie constraint.

\section{Discussion and Conclusion}

The steel bar reinforced triplets failed by shear of the bar, exhibiting a near perfect elasto-plastic characteristic, suggesting shear failure of the steel dominates the behavior of the joint.

The aluminum tube reinforced triplets failed by splitting of the brick, as can be seen in Figure 1. Initially behavior was similar to an un-reinforced triplet but with much greater failure strain. This suggests that initial response is governed by the mortar stiffness, and once the bond is broken the tube deforms until the shear stiffness of the brick is mobilized.
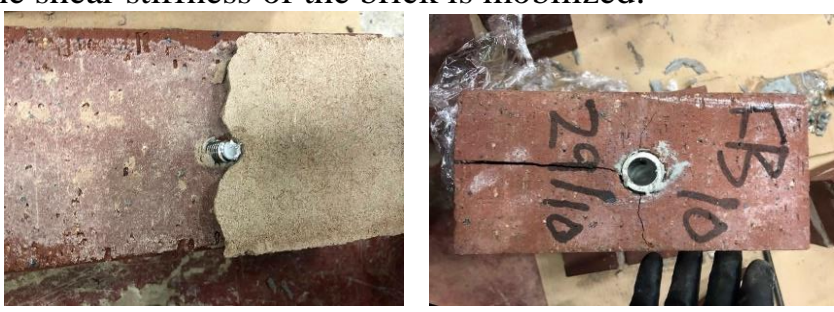

Fig. 1. Failure mechanisms identified in a) bar reinforced, and b) tube reinforced triplets [4].

Grouted reinforcement can reinstate the longitudinal shear capacity of a multi-ring masonry arch which has suffered ring separation. Small diameter bar will produce shear failure in the radial pin but use of a larger diameter tube will change the failure mechanism to splitting of the brick. The choice of pin size and type must be made carefully in order to avoid a future failure which is unacceptable to the bridge owner.

\section{References}

1. Melbourne, C. \& Alnumaimi, M. M.: The behaviour of multi-ring brickwork arches subjected to cyclic loading. In: ARCH'01 - $3^{\text {rd }}$ International Conference on Arch Bridges, Paris, pp. 243-247 (2001).

2. Melbourne, C. \& Gilbert, M.: The behaviour of multi-ring brickwork arch bridges containing ring separation. British Masonry Society Proceedings (4), 218-222 (1994).

3. Naggasa, A., Augusthus-Nelson, L. \& Haynes, J.: Use of finite element analysis to investigate the structural behaviour of masonry arch bridges subject to foundation settlement. In: $10^{\text {th }}$ International Masonry Conference. Milan, Italy, pp. 518-526 (2018).

4. El-Basir, F.: Behaviour of reinforced brick triplets in shear. B.Eng Dissertation, University of Salford, (2019). 